\title{
Language lateralisation measured across linguistic and national boundaries
}

Markus Hausmann ${ }^{1 *}$, Marc Brysbaert ${ }^{2}$, Lise van der Haegen ${ }^{2}$, Jörg Lewald ${ }^{3}$, Karsten Specht $^{4,5}$, Marco Hirnstein ${ }^{4}$, Julie Willemin ${ }^{6}$, Jack Barton $^{1}$, Delia Buchilly ${ }^{6}$, Florian $\mathrm{Chmetz}^{6,7}$, Maja Roch $^{8}$, Sanne Brederoo ${ }^{9}$, Nele Dael ${ }^{6}$, Christine Mohr $^{6}$

${ }^{1}$ Department of Psychology, University of Durham, United Kingdom

${ }^{2}$ Department of Experimental Psychology, Ghent University, Belgium

${ }^{3}$ Faculty of Psychology, Ruhr-Universität Bochum, Germany

${ }^{4}$ Department of Biological and Medical Psychology, University of Bergen, Norway

${ }^{5}$ Department of Education, The Arctic University of Norway, Troms $\varnothing$, Norway

${ }^{6}$ Institute of Psychology, University of Lausanne, Switzerland.

${ }^{7}$ Faculty of Biology and Medicine, Centre for Psychiatric Neurosciences University of Lausanne, Switzerland.

${ }^{8}$ Department of Developmental Psychology and Socialisation, University of Padua, Italy

${ }^{9}$ Department of Experimental Psychology, University of Groningen, The Netherlands

* Corresponding authors: Markus Hausmann, Department of Psychology, University of Durham, Science Campus, South Road, DH1 3LE Durham, UK

(markus.hausmann@durham.ac.uk) 


\section{Acknowledgement}

We thank Roger Vestb $\varnothing$, Therese Buch, Åse Lager, Siri Håland Medhaug, Lydia Brunvoll Sand $\varnothing$, Aylin Aure, Kaia Brun, Nilei Kattarina Huang, Hanna Margrete Horpestad (all from University of Bergen), Katharina Ackermann, Tobias Albrecht, Mira Beermann, Benedikt Claus, Julia Hansmann, Nina Kanschik, Marvin Kühn, Anastasia Lynnyk, Sandra Nistahl, Jan Nitschke, Sally M. Rogalla, Jörn A. Quent, Sidney Wach, Ricarda Weiland (all from Ruhr-Universität Bochum), Sophie Jöbkes, Lukas Kowald, Heike Schuler, and Louisa La Porta (all from University of Groningen) for help with running the experiments. J.L. was supported by the German Research Foundation (DFG, LE 673/2-1). M.Hi. and K.S. were supported by Bergen Research Foundation projects (BFS2016REK03 and „When a sound becomes speech"). S.B. was supported by the grant 022.004 .008 of the Netherlands Organisation for Scientific Research (NWO). 


\begin{abstract}
The visual half-field technique has been shown to be a reliable and valid neuropsychological measurement of language lateralisation, typically showing higher accuracy and faster correct responses for linguistic stimuli presented in the right visual field (RVF) than left visual field (LVF). The RVF advantage corresponds to the well-known dominance of the left hemisphere (LH) in processing language(s). However, clinical and experimental neuroscientists around the globe use different variations of the visual half-field paradigm, making direct comparisons difficult. The current study used a word/non-word visual half-field paradigm with translingual stimuli. In total, 496 participants from seven European countries were investigated: Belgium (64), England (49), Germany (85), Italy (48), The Netherlands (87), Norway (51), and Switzerland (126), covering six international languages (Dutch, English, French, German, Italian, Norwegian). All language groups revealed a significant RVF/LH advantage in accuracy and reaction times that accounted for up to $26.1 \%$ of the total variance in performance. We found some variation in the degree of the RVF/LH advantage across language groups, accounting for a maximum of $3.7 \%$ of the total variance in performance. The RVF/LH advantage did not differ between subsamples speaking English, French or German as first or second languages or between monolingual and early/late bi/multilinguals. The findings suggest that the translingual lexical decision task (TLDT) is a simple but reliable measurement of language lateralisation that can be applied clinically and experimentally across linguistic and national boundaries.
\end{abstract}

Keywords: Lexical decision task, lateralisation, hemispheric asymmetry, languages, visual half-field paradigm 


\section{Introduction}

The dominant role of the left cerebral hemisphere in processing language is a fundamental principle of functional brain organization and one of the most reliable findings in laterality research (Hugdahl, 2000; Ocklenburg \& Güntürkün, 2018). Historically, the first evidence of the superior role of the left hemisphere (LH) in language processing came from clinical studies of patients with unilateral cerebral lesions (Broca, 1865; Wernicke, 1874). More recently cognitive neuroscientists have used neuroimaging techniques (e.g., EEG, $\mathrm{fMRI}, \mathrm{MEG}, \mathrm{PET}$ ) to localize specific language functions in clinical and non-clinical groups (e.g., Hickok \& Poeppel, 2007; Vigneau et al., 2006). Although these techniques proved to be of clinical and experimental use, neuroimaging techniques are costly, time consuming and not available to all researchers (Bourne, 2006). Therefore, clinicians and researchers have been and remain interested in localising language functions using reliable noninvasive experimental techniques that are low-priced, relatively simple and easy to administer.

One well-established behavioural technique is the visual half-field (VHF) paradigm (e.g., Bourne, 2006, for overview). Here, words or non-words are briefly $(<150 \mathrm{~ms})$ presented in either the left (LVF) or right visual field (RVF). Due to the visual projections (i.e., visual projections in each hemisphere represent the contralateral visual field), stimuli presented in the RVF are primarily projected to the contralateral LH and vice versa. Participants who are left dominant for language, typically reveal lower error rates and faster correct responses when stimuli were presented to the RVF/LH.

Originally, the VHF paradigm has been used as a simple, non-invasive and 
cost-effective technique to localise language processes, primarily in patients after unilateral lesions or patients with callosal deficits (e.g., Gazzaniga, Bogen, \& Sperry, 1965; Kimura, 1961; Lassonde \& Bryden, 1990; Lassonde, Bryden, \& Demers, 1990; Sperry, 1982). However, despite the advantages mentioned earlier, the VHF technique has also been criticised because of several inconsistent findings (e.g., Krach, Chen, \& Hartje, 2006) and intra- and inter-individual differences in language lateralisation. For example, although language lateralisation has been assumed to be a trait characteristic of the human brain, several studies found developmental changes in the degree and sometimes even the direction of the RVF/LH language advantage (e.g., Bishop, 2013). Even in adults, it has been shown that the LVF/RH advantage in verbal VHF tasks can change within relatively short-term intervals (e.g., Hausmann et al., 2002; Hausmann, Hodgetts, \& Eerola, 2016; Mohr, Michel, et al., 2005), which might explain some of the observed intra- and inter-individual differences in language lateralisation.

Overall, if run properly, VHF studies have shown good validity, for example, when compared to neuroimaging techniques (e.g., Hunter \& Brysbaert, 2008; Weis et al., 2008). Hunter and Brysbaert (2008) reported significant positive correlations between laterality indices as measured by visual half-field paradigms and $\mathrm{FMRI}$ in word $(r=.63)$ and picture naming $(r=.77)$. Such recent studies revived the notion that results from behavioural half-field paradigms should be taken seriously in the theoretical and clinical domain (Carey \& Johnstone, 2014; Hugdahl, 2011; Van der Haegen, Cai, Seurinck, \& Brysbaert, 2011).

VHF studies have generally shown to be of satisfying reliability (e.g., Brysbaert \& D’Ydewalle, 1990; Chiarello, Dronkers, \& Hardyke, 1984; Fennell, 
Bowers, \& Satz, 1977; Hausmann \& Güntürkün, 1999; Hines, Fennell, Bowers, \& Satz, 1980; for a review see Voyer et al., 1998). However, validity and reliability of VHF tasks to identify the language-dominant hemisphere largely depend on some critical methodological aspects of the VHF paradigm, such as backward masking, sufficient number of observations, tachistoscopic (brief) stimulus presentation, and bilateral presentation of stimuli in LVF and RVF (Beaumont, 1982; Bourne, 2006; Hunter \& Brysbaert, 2008). For example, Hunter and Brysbaert (2008) noticed that previous studies observed larger and more stable VHF differences when, in each trial, two different stimuli were presented simultaneously in the LVF and RVF than when only one stimulus was presented either in the LVF or in the RVF (Boles, 1987, 1990, 1994; see also lacoboni \& Zaidel, 1996). The LVF stimulus has to compete with the RVF stimulus during bilateral presentation, which is easier when the target stimulus is presented in the dominant hemisphere and the competing stimulus in the non-dominant hemisphere than vice versa. If these critical methodological issues are taken into consideration when planning an experiment, the VHF paradigm can be a useful tool to localise language functions in a clinical context and in healthy populations of different ages.

Although ensuring that the VHF paradigm can be used as a valid and reliable tool for the assessment of language lateralisation, VHF studies can differ substantially in the above mentioned characteristics, sometimes even within single studies, which makes the comparison between studies and integration of findings difficult (Beaumont, 1982; Bourne, 2014). Direct comparisons between studies are additionally hindered because of the different languages spoken in different cultures, studies, and laboratories around the globe (see also Willemin et al., 2016). 
Although researchers seem to implicitly assume that verbal stimuli (e.g., words) in different languages will produce a similar directional bias, this has not been systematically investigated yet.

The current multicentre study aimed to develop a translingual VHF task that allows reliable measurement of language lateralisation across linguistic and national boundaries by using a stimulus set of nouns that have the same meaning in many languages and therefore can be administered internationally. This translingual VHF task has recently been used in a published pilot study investigating 100 mono- and multilingual participants from a dominantly French-speaking university in Switzerland (Willemin et al., 2016). Participants had to decide whether pairs of stimuli projected to the LVF and RVF included a meaningful word or not. The results suggested a reliable RVF/LH advantage in both accuracy (ACC) and response time (RT), irrespective of participants' sex, handedness, and bilingualism. To expand these findings, the current study recruited a large sample size of 563 participants from seven Universities in Europe, including Bergen (Norway, NO), Bochum (Germany, DE), Durham (United Kingdom, UK), Ghent (Belgium, BE), Groningen (The Netherlands, NL), Lausanne (Switzerland, CH), and Padua (Italy, IT), covering six spoken languages, including Dutch (DU), English (EN), French (FR), German (GE), Italian (IT) and Norwegian (NO).

Based on previous results (Willemin et al., 2016), we hypothesised a reliable RVF/LH advantage in ACCs and RTs across languages, regardless of how many languages participants speak and whether a specific second language was acquired early or late. It was further hypothesised that a consistent left hemispheric advantage in TLDT also occurs when asymmetry indices (Als) were applied which 
take the individual performance differences into account (see Methods section for more details). Given that about $87 \%$ of right handers and $65 \%$ of left-handers are assumed to be LH dominant for language (Papanicolaou et al., 2008), we predicted positive Als in about $85 \%$ of all language groups. Finally, we predicted a negative asymmetry-performance relationship as was found previously for verbal VHF tasks (e.g., Boles et al., 2008; Hirnstein, Leask, Rose, \& Hausmann, but also see Chiarello et al., 2009).

\section{Method}

\section{Participants}

We recruited 563 participants (373 women) through personal contact, classroom advertisement and public advertisement in and around the university campuses. At each site, one or more experimenters recruited and tested the local participants. Questionnaires and the TLDT manual and instructions were translated by native speakers and double-checked by a second native speaker. All participants reported to have (i) normal or corrected to normal vision, (ii) no previous history of psychiatric or neurological illness, (iii) not taking any medication affecting the CNS. The majority of participants were remunerated for their participation (e.g., course credit).

The Belgian participants came from the Dutch-speaking, Northern half of the country. The Swiss participants came from the French-speaking regions. Switzerland is divided into four language regions with, as of 2016 (Bundesamt für Statistik, Schweizerische Eidgenossenschaft, 2018), Swiss-German making the largest part (63\%), followed by French (22\%), Italian (8\%), and finally Romansh (0.5\%). The 
higher education opportunities are limited in the Italian-speaking part of Switzerland and students frequently need to leave their language region. Thus, in Lausanne, we had also access to Italian speakers.

After participants were informed about the experimental procedures, they provided written informed consent prior to participation. The study was conducted in accordance with the guidelines of the declaration of Helsinki (World Medical Association, 2001) and was approved by local ethic committees at each site, where appropriate.

\section{Materials}

Demographic information and handedness

A first self-report questionnaire assessed demographic information (e.g., gender, age, health, languages spoken). In addition, the well-established Edinburgh Handedness Inventory (Oldfield, 1971) was used to measure participants' hand preferences. The laterality index $(\mathrm{LI})$ provided by this test is calculated as $[(R-L) /(R+$ L)] $\times 100$, resulting in values between -100 and 100 , describing a continuum between consistent sinistrality and consistent dextrality, respectively. Although there is a significant relationship between handedness and language laterality (Rasmussen \& Milner, 1975), handedness is only an imperfect proxy for language lateralisation (Bishop, 2013; Van der Haegen, Westerhausen, Hugdahl, \& Brysbaert, 2013). Therefore, left-handed participants and participants without consistent hand preferences were included in the current study. Table 1 shows mean age and mean $L Q, S D$ and range for each language group (first language) for whom the data were included in the analysis (see below). 
Table 1. Mean age and handedness scores (and standard deviations and ranges) according to sex and language group.

\begin{tabular}{lcccc}
\hline Language & Sex & N & Age (years) & Handedness (LI) \\
\hline $\begin{array}{l}\text { Dutch } \\
(n=109)\end{array}$ & M & 85 & $21.79 \pm 4.02(17.0-47.0)$ & $82.66 \pm 30.15(-100.00-100.00)$ \\
English & $F$ & 36 & $23.17 \pm 5.20(18.0-39.0)$ & $81.00 \pm 36.69(-100.00-100.00)$ \\
$(n=53)$ & $M$ & 17 & $25.41 \pm 5.81(19.0-41.0)$ & $85.00 \pm 21.31(25.00-100.00)$ \\
French & $F$ & 63 & $21.89 \pm 5.50(18.0-53.0)$ & $36.55 \pm 70.20(-100.00-100.00)$ \\
$(n=86)$ & $M$ & 23 & $23.67 \pm 5.21(17.0-42.0)$ & $36.67 \pm 60.82(-80.00-100.00)$ \\
& & & & \\
German & $F$ & 88 & $22.82 \pm 5.26(18.0-49.0)$ & $86.97 \pm 15.27(36.36-100.00)$ \\
$(n=127)$ & $M$ & 39 & $24.82 \pm 7.17(18.0-49.0)$ & $75.50 \pm 31.61(-60.00-100.00)$ \\
Italian & $F$ & 49 & $24.31 \pm 4.50(19.0-38.0)$ & $80.32 \pm 34.51(-70.00-100.00)$ \\
$(n=70)$ & $M$ & 21 & $26.62 \pm 4.57(20.0-35.0)$ & $46.43 \pm 75.41(-100.00-100.00)$ \\
Norwegian & $F$ & 26 & $22.35 \pm 2.26(19.0-30.0)$ & $67.94 \pm 54.72(-80.00-100.00)$ \\
$(n=51)$ & $M$ & 25 & $22.64 \pm 1.96(20.0-27.0)$ & $70.85 \pm 48.11(-100.00-100.00)$ \\
\hline Total & $F$ & 347 & $22.52 \pm 4.79(17.0-53.0)$ & $72.50 \pm 46.51(-100.00-100.00)$ \\
$(N=496)$ & $M$ & 149 & $23.99 \pm 5.30(17.0-49.0)$ & $65.64 \pm 49.70(-100.00-100.00)$ \\
\hline
\end{tabular}

We have a large mobility within the Europe Union. As a consequence, students' first language at a particular site did not necessarily match the language spoken at a university site. Moreover, to compare whether results for a given language differed for different locations, we a priori recruited German speakers in Groningen (NL) and Italian speakers in Lausanne (CH) (Table 2). For example, 40 out of 87 participants (46.0\%) recruited at the University of Groningen (NL) reported German to be their first language. Also, 377 out of the total sample of 496 participants (76.0\%) reported to speak at least one additional language. Time of acquisition (in years) of additional languages was established by simply asking participants. The literature often suggests an acquisition age of 6 years as cut-off to classify early and late bi-multilinguals (e.g., Hausmann, Durmusoglu, Yazgan \& 
Güntürkün, 2004; Hull \& Vaid, 2007; Tao, Marzecova, Taft, Asanowicz, \& Wodniecka, 2011; Willemin et al., 2016). Table 2 shows the number of participants speaking a particular first and second language at each site. Forty-eight participants (9.7\%) acquired the second language before the age of 6 years (usually at home), 276 participants (55.6\%) acquired the second language after the age of 6 years (usually at school). In the following, we refer to these two groups as early and late bi/multilingual, respectively. With regard to the French and Italian language group, part of the sample was tested in Willemin et al. (2016) who investigated language lateralisation in left-handers, mixed-handers and right-handers (among other things). The recruitment of three handedness groups In Willemin et al. (2016) also explains the low mean handedness score in the French-speaking sample as compared to the other language groups. 
Table 2. Number of participants speaking Dutch (DU), English (EN), French (FR), German (GE), Italian (IT), Norwegian (NO), and other/unknown languages (OT) as first and second language at each site.

\begin{tabular}{|c|c|c|c|c|c|c|c|c|c|c|c|c|c|c|c|}
\hline \multirow[t]{2}{*}{ Site } & \multirow[t]{2}{*}{$\mathbf{N}$} & \multicolumn{7}{|c|}{ 1st language } & \multicolumn{7}{|c|}{ 2nd language } \\
\hline & & DU & EN & FR & GE & IT & NO & OT & DU & EN & FR & GE & IT & NO & От \\
\hline Bochum (DE) & 85 & & & & 85 & & & & & 79 & & & 1 & & 4 \\
\hline Durham (UK) & 49 & & 49 & & & & & & & & 6 & & & & 11 \\
\hline Ghent (BE) & 64 & 64 & & & & & & & & 20 & 30 & & 1 & & 5 \\
\hline Groningen (NL) & 87 & 45 & 2 & & 40 & & & & & 69 & 5 & 3 & & & 4 \\
\hline Lausanne $(\mathrm{CH})$ & 126 & & 1 & 86 & 2 & 37 & & & & 27 & 14 & 15 & 3 & & 11 \\
\hline Padua (IT) & 34 & & 1 & & & 33 & & & & 18 & & & 1 & & \\
\hline Bergen (NO) & 51 & & & & & & 51 & & & 46 & 2 & & & & 3 \\
\hline Total & 496 & 109 & 53 & 86 & 127 & 70 & 51 & & & 258 & 57 & 18 & 6 & & 38 \\
\hline
\end{tabular}

Translingual lexical decision task (TLDT)

Word selection (see also Willemin et al., 2016). For the stimulus selection, we started from a database of 1700 words belonging to both the English and Dutch vocabulary. We determined four to six letter words that also exist in French, German, and Italian (online Leo dictionary http://dict.leo.org/, 2012). For these 280 words, we calculated word frequency (Table 3) and imageability for English and French using respectively N-Watch (Davis, 2005) and Lexique 3.80 (New, Pallier, Brysbaert, \& Ferrand, 2004). We then created quartiles for the word frequencies in the two languages. We retained words when they fell into the same quartile for English and French word frequency distribution. To avoid words of very low frequency, we included words that fell into the $2^{\text {nd }}, 3^{\text {rd, }}$ or $4^{\text {th }}$ quartile, leaving us with 16 lowercased words: agenda, alibi, aura, casino, film, gala, garage, jazz, jury, 
menu, radio, piano, snob, studio, taxi, virus (see Willemin et al., 2016, for more details). We did not apply the same procedure to Dutch, German, Italian and Norwegian, because this would have further reduced the word stimulus set. However, native speakers of these languages confirmed that the 16 remaining words were common words in these languages. Using these 16 words, we created non-words using the pseudoword creator "Wuggy" (Keuleers \& Brysbaert, 2010). The selection criteria for the non-word stimulus and the list of non-words and word pairs can be found in Willemin et al. (2016). The full list of word and non-word combinations can be found in Table 4. 
Table 3. Word frequency of stimuli in English and French (frequency per million words.)

\begin{tabular}{llcccc}
\hline \multicolumn{5}{c}{} & \multicolumn{5}{c}{ Word frequency } \\
\cline { 2 - 6 } Word & $\begin{array}{c}\text { English } \\
\text { (CELEX) }\end{array}$ & $\begin{array}{c}\text { French } \\
\text { (Lexique 3.80) }\end{array}$ & $\begin{array}{c}\text { Dutch } \\
\text { (SUBTLEX-NL) }\end{array}$ & $\begin{array}{c}\text { German } \\
\text { (SUBTLEX-DE) }\end{array}$ & $\begin{array}{c}\text { Italian } \\
\text { (SUBTLEX-IT) }\end{array}$ \\
\hline Agenda & 8.66 & 5.55 & 12.21 & 0.47 & 6.73 \\
Alibi & 3.46 & 7.88 & 15.07 & 8.03 & 13.85 \\
Aura & 4.80 & 9.66 & 1.62 & 2.64 & 2.02 \\
Casino & 3.74 & 10.35 & 16.12 & 6.50 & 53.40 \\
Film & 88.16 & 49.53 & 174.28 & 266.70 & 176.30 \\
Gala & 0.84 & 3.14 & 1.56 & 1.26 & 1.71 \\
Garage & 22.79 & 23.32 & 29.13 & 14.84 & 17.62 \\
Jazz & 8.49 & 7.75 & 6.97 & 3.62 & 5.99 \\
Jury & 29.11 & 5.14 & 31.17 & 5.04 & $22.59 *$ \\
Menu & 7.26 & 10.95 & 6.63 & 0.20 & 5.67 \\
Radio & 83.97 & 50.54 & 14.11 & 2.01 & 238.42 \\
Piano & 26.03 & 28.51 & 58.7 & 34.49 & 55.84 \\
Snob & 2.29 & 1.06 & 1.99 & 1.10 & 3.25 \\
Studio & 22.01 & 19.90 & 17.08 & 23.15 & 66.48 \\
Taxi & 29.61 & 41.22 & 50.84 & 50.51 & 39.03 \\
Virus & 9.33 & 15.20 & 28.91 & 42.36 & 18.48 \\
\hline
\end{tabular}

* This word is written giuria in Italian

Sources: SUBTLEX-UK (Van Heuven, Mandera, Keuleers, \& Brysbaert, 2014), Lexique (New, Pallier, Brysbaert, \& Ferrand, 2004), SUBTLEX-NL (Keuleers, Brysbaert, \& New, 2010), SUBTLEX-DE (Brysbaert, Buchmeier, Conrad, Jacobs, Bölte, \& Böhl, 2011), SUBTLEX-IT (Crepaldi, Keuleers, Mandera, \& Brysbaert, 2013). For Norwegian, there are no data. 
Table 4. Word stimuli and non-word stimuli as presented in pairs in the translingual lexical decision task. Stimuli highlighted in bold are meaningful words in Dutch, English, French, German, and Italian. The Norwegian words for "gala", "garage", "menu", and "snob" are spelt "galla", garasje", "meny", and "snobb", respectively. The non-word "snik" is a word in Dutch, and should be adjusted to "snil" (the original "snik" was still used in the current study). In addition, it should be noted that "jury" is not an Italian loan word (it is written "giuria"), while "pieni" is a word (plural form of the adjective "pieno", full). Also, "eure" is a German word ("yours"), while "lara" is a proper name. It is recommended that future studies check the orthotactic structure of the non-words they employ, as they may act as words in some languages and as impermissible non-words in others (e.g. "fibm" or "tawl"). 


\begin{tabular}{|c|c|}
\hline agenda & asenga \\
\hline Alibi & acipi \\
\hline aura & aita \\
\hline casino & caniso \\
\hline film & fitz \\
\hline gala & dara \\
\hline garage & lapage \\
\hline jazz & jaik \\
\hline jury* & jula \\
\hline menu & besu \\
\hline piano & pieni \\
\hline radio & rapoo \\
\hline snob & ssib \\
\hline studio & slugio \\
\hline taxi & taia \\
\hline virus & gilus \\
\hline lara & vata \\
\hline sneg & snik \\
\hline cadisy & canisi \\
\hline eure & euta \\
\hline janz & japt \\
\hline beny & bevu \\
\hline asanca & asande \\
\hline gitus & giris \\
\hline turnex & turmel \\
\hline slougou & slougue \\
\hline vavade & vavege \\
\hline pueni & peani \\
\hline juto & jula \\
\hline taht & tawl \\
\hline rageu & rapea \\
\hline firl & fibm \\
\hline
\end{tabular}

Note: Each pair is shown in the above sequence, but also in reversed order. The bold stimuli are meaningful words in Dutch, English, French, German, and Italian. * "jury" is not an Italian loan word (Italian spelling "giuria") 
TLDT procedure. For each trial, two stimuli, either word(s) and/or non-word(s), were presented simultaneously to the RVF and LVF. All stimuli were presented (in lower case, black, Courier New, 12 points) on a computer screen on a white background. Each trial started with a fixation cross presentation for $1000 \mathrm{~ms}$, followed by two stimuli presented briefly (100 ms). The brief bilateral stimulus presentation guaranteed adequate control for eye movement in previous VHF experiments with verbal stimuli (Beaumont, 1982). Studies that directly monitored eye movements reported failures of fixation on only $0.5 \%$ of trials (Geffen, Bradshaw \& Nettleton, 1972, but see also Bourne, 2006).

Participants had 2000 ms to decide whether a meaningful word was presented in the LVF or RVF, before the next trial was initiated. Participants were instructed to indicate by button press on a keyboard whether they saw a meaningful word to the left ('respond with left index finger on a left-sided button'), to the right ('respond with right index finger on a right-sided button') or saw no meaningful word on either side ('press space bar with both thumbs'). We presented each letter string combination four times in randomized order: word/non-word (16 pairs), nonword/word (16 pairs) and 32 non-word/non-word pairs (the 16 original nonword/non-word pairs were also shown in reversed order).

Regarding the repetition of the stimuli, Hunter and Brysbaert (2008) recommended to present the stimuli both in LVF and in RVF, so that there is no confound between VHF and words used, especially if individual data are to be used. Whether repetitive presentation of stimuli has any effects on language lateralisation is less clear (see Krach et al., 2006). Brysbaert and d'Ydewalle (1990) reported no differences in VHF asymmetries for words presented five times in subsequent 
blocks. Because of the small number of translingual stimuli, our task requires the repetition of stimuli, given that a minimum of 40 observations per person and per condition is recommended for properly powered studies (Brysbaert \& Stevens, 2018).

Correct responses (\%) and mean response times of correct responses were calculated for LVF and RVF. In line with previous studies (Allison, Puce, \& McCarthy, 2000; Cornelissen, Tarkiainen, Helenius, \& Salmelin, 2003; Ratcliff, Gomez, \& McKoon, 2004), individual response latencies faster than 200 ms were excluded.

The experiment was programmed using DMDX (Forster \& Forster, 2003). Participants were seated in front of a computer screen with a screen-eye distance of $57 \mathrm{~cm}$, so that $1 \mathrm{~cm}$ corresponds to $1^{\circ}$ of visual angle. The stimulus eccentricity was between $2^{\circ}$ to $5^{\circ}$ of visual angle horizontally and $0.5^{\circ}$ of visual angle vertically.

Prior to the first experimental trial, participants performed 10 practice trials with stimuli that were not used in the actual experiment. In total, participants performed 256 experimental trials with a break after 128 trials which varied from 1 $\min$ to 5 min between participants. Participants were instructed to fixate the fixation cross at all times and to respond as fast and accurately as possible. The number of correct lexical decisions and mean reaction times for correct word decisions were registered for LVF and RVF trials. One testing session took about 30 $45 \mathrm{~min}$.

\section{Data Analysis}

We excluded participants based on participants' task performance. Twenty- 
eight participants (5.0 \%) were excluded because performance for stimuli presented in their dominant VHF was not significantly above chance level. We also excluded 27 participants (4.8\%) whose performance for stimuli presented in the non-dominant VHF (either LVF or RVF) was significantly below chance level. The thresholds above/below chance were derived based on binomial tests (Bortz et al., 2000). Finally, five participants were excluded because their first language was underrepresented in our sample and therefore did not allow statistical analysis: Albanian $(n=3)$, Portuguese $(n=1)$, and Turkish $(n=1)$. The final sample consisted of 496 participants ( 347 women) with a mean age of 23 years (range $17-53$ years) (see Table 1).

For the analysis, we analysed the percentages in ACCs and RTs for correct word decisions. In a second analysis, we used asymmetry indices (Als), calculated as [(RVF performance - LVF performance)/(RVF performance + LVF performance)] $\times$ 100 , resulting in values between -100 and 100 , describing a continuum between an expected RVF/LH advantage and unexpected LVF/RH advantage in language lateralisation. Several previous neuroimaging and behavioural studies have successfully applied Als (also called laterality index) to determine the degree of language lateralisation in brain activation and performance data (e.g., Hirnstein, Hausmann, \& Güntürkün, 2008; Hirnstein et al., 2010; Knecht et al., 2003; Rutten, Ramsey, van Rijn, \& van Veelen, 2002; Seghier, 2008) and "to reliably identify hemispheric dominance in language" (Hunter \& Brysbaert, 2008, p. 322).

Due to the large number of participants speaking more than one language, we also compared language lateralisation of subsamples speaking English, French, and 
German as first and second language. We also tested whether bilinguals differed in language lateralisation by dividing the entire sample into subgroups of monolinguals, early and late bilinguals who acquired the second language before or after the age of 6 years. Given that no information about acquisition time of the second language was available from the Norwegian sample, the Bergen data were excluded from the analyses on bilingualism. Finally, the large sample size of the current study allowed investigating the on-going debated relationship between degree in language lateralisation (operationalized by $\mathrm{Al}$ ) and the overall performance (averaged ACCs and RTs in LVF and RVF). Due to group differences in handedness (see below), handedness scores were always included as covariate in the statistical analyses. Post hoc tests were alpha-adjusted for multiple testing (Bonferroni correction), if not otherwise specified.

\section{Results}

Hand preference

Hand preference scores (LIs) were subjected to a 2 sex (male, female) x 6 language groups (Dutch, English, French, German, Italian, Norwegian) ANOVA which revealed a significant main effect of language group, $F(5,443)=10.53, p<.001, \eta_{p}{ }^{2}=.11$. The French-speaking group had the lowest hand preference scores which differed significantly from all other groups (all $p<.05)$. Twenty-four participants $(27.9 \%)$ of the French-speaking subsample revealed a negative score, which is not surprising given that non-right-handers in Willemin et al.'s (2016) study were preselected. The other four language groups (Dutch, German, English, Italian, Norwegian) did not 
differ significantly in handedness (all $p>.05$ ). Neither the main effect of sex nor the interaction between sex and language group approached significance, both $F \leq 2.23$, both $p \geq .136$, both $\eta_{p}{ }^{2} \leq .02$. A summary of the handedness scores in the current sample is shown in Table 1. Because of the significant group differences in hand preferences across language groups, handedness scores were used as covariate in all subsequent analyses. There were no differences in handedness scores between monolinguals $(M \pm S D ; 71.47 \pm 49.61)$, early bi/multilinguals $(65.49 \pm 45.82)$ and late bi/multilinguals $(70.97 \pm 46.28), F(2,401)=0.28, p=.76, \eta_{p}{ }^{2}<.01$.

\section{Translingual lateralised lexical decision task}

Accuracies. ACCs (\%) in word trials were subjected to a 2 (LVF, RVF), 2 (male, female) x 6 (Dutch, English, French, German, Italian, Norwegian) mixed ANCOVA.

Handedness scores were included as covariate. As expected, the ANCOVA revealed a significant and large RVF/LH advantage, $F(1,442)=156.34, p<.00001, \eta_{p}{ }^{2}=.261$.

The main effect of language group was significant, $F(5,442)=15.03, p<.00001, \eta_{p}{ }^{2}$ $=.145$. Mean ACCs for participants speaking English and Dutch were higher $(M \pm$ SEM; $72.41 \pm 1.56$ and $70.10 \pm 1.22$, respectively) than for participants speaking French $(66.65 \pm 1.34)$, Norwegian $(62.37 \pm 1.47)^{1}$, German $(60.29 \pm 1.20)$, and Italian (59.76 \pm 1.38 ). Post hoc comparisons revealed that participants speaking Dutch and English had higher ACCs than participants speaking German, Italian, and Norwegian

\footnotetext{
${ }^{1}$ All Norwegian participants in the current sample completed the TLDT with the original spelling and were instructed to identify English words. When compared to a small pilot sample $(n=9)$ completing the TLDT with Norwegian spelling, using a mixed ANCOVA with the repeated measures factor visual half-field (LVF, RVF), the between-participants factor Spelling (Norwegian versus English), and handedness as covariate, accuracies with Norwegian spelling $(68.39 \pm 3.52)$ were somewhat higher than with English spelling $(62.39 \pm 1.48)$. However, the main effect or interaction involving the factor Spelling were not significant, neither for reaction times, nor for accuracies, all $F \leq 2.47$, all $p \geq .122$, all $\eta_{p}{ }^{2} \leq .042$.
} 
(all $p \leq .001$ ). In addition, French speaking participants had higher ACCs than German $(p=.009)$ and Italian speaking participants $(p=.005)$. No other language group comparisons were significant, $p \geq .089$. No other main effect or interactions were significant, all $F \leq 1.97$, all $p \geq .082$, all $\eta_{p}^{2} \leq .022$. Mean accuracy and standard errors are shown in Figure 1.

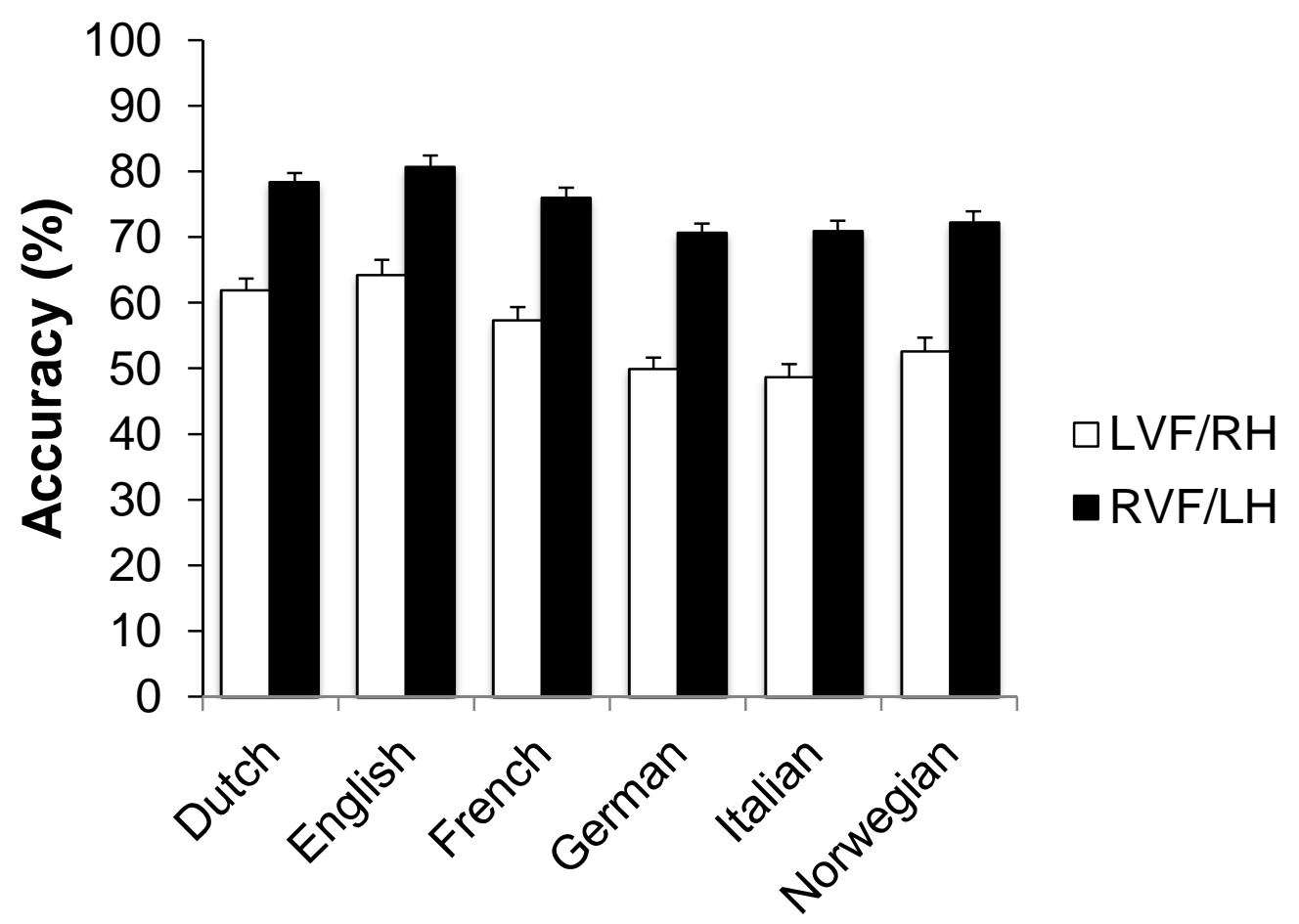

Figure 1. Mean ACC (\%) and standard errors for both visual half-fields (LVF/RH, RVF/LH) and six language groups (Dutch, English, French, German, Italian, Norwegian).

Response times. RTs (ms) in correct word trials were subjected to the same mixed ANCOVA as used for ACCs. Again, the ANCOVA revealed a significant, medium-sized, RVF/LH advantage, $F(1,442)=49.33, p<.00001, \eta_{p}{ }^{2}=.100$. Also, the main effect of language group was significant, $F(5,442)=14.79, p<.00001, \eta_{p}^{2}=.14$. The Dutch 
speaking subsample revealed the fastest responses ( $681 \pm 11.96)$, followed by German (717 \pm 11.8), English (738 \pm 15.3), Norwegian (777 \pm 14.2$)$, French (783 \pm 13.1), and Italian speaking samples (818 \pm 13.5$)$. Dutch speaking participants responded significantly faster than participants speaking French, Italian, and German (all $p<.001$ ). German-speaking participants responded significantly faster than participants speaking French, Italian, and Norwegian (all $p<.022$ ). Finally, the English speaking sample responded significantly faster than Italian speaking participants $(p=.001$, all other $p \geq .057)$. The VHF $x$ language group interaction was also significant, $F(5,442)=3.39, p=.005, \eta_{p}{ }^{2}=.037$. Although post hoc t-tests revealed significant RVF/LH advantages for all languages, all $t \geq 4.61, p<.0001$, with effect sizes (Cohen's $d$ corrected for dependence between means: Morris \& DeShon, 2002 ) in the medium range (Dutch: 0.443 , German: 0.584 , French: 0.633 , Italian: 0.759; Norwegian: 0.778; English: 0.778), the only significant difference in the magnitude of the RVF/LH advantages was between the Dutch and Italian sample ( $p=$ .005). Finally, the interaction between sex and language group was significant, $F(5$, $442)=3.37, p=.005, \eta_{p}^{2}=.037$. Post hoc tests (Bonferroni corrected) revealed that in the German speaking sample, men $(694 \pm 19.2)$ responded faster than women $(753 \pm 11.7 . t(125)=2.73, p=.042)$. There were no sex differences in the other language groups, all $t \leq 2.55$, all $p>.05$ ). No further effects approached significance (all $p$-values $>.05$ ). Mean response times and standard errors are shown in Figure 2. 


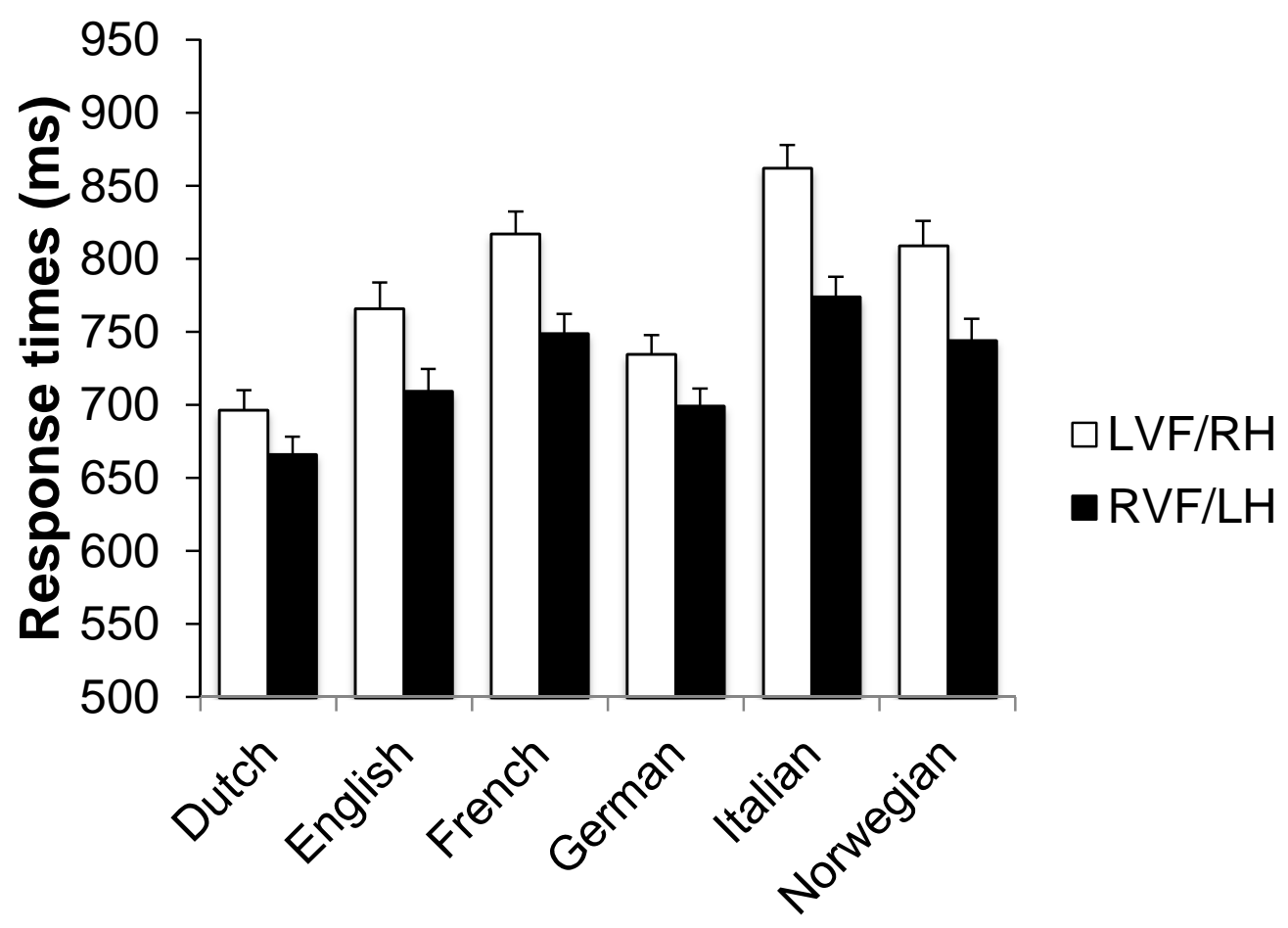

Figure 2. Means RTs (ms) and standard errors for both visual half-fields (LVF/RH, RVF/LH) and six language groups (Dutch, English, French, German, Italian, and Norwegian).

\section{Asymmetry indices}

Both previous ANCOVAs of ACCs and RTs revealed significant main effects of language group. To investigate whether visual half-field differences across languages groups were confounded by group-specific performance differences, we also calculated Als for both dependent variables using the formula: [(RVFLVF)/(RVF+LVF)] $\times 100$ (see Methods). This index was also used to analyse whether language groups differed in the number of participants showing positive Als, indicating a RVF/LH advantage. Frequencies of participants with positive (typical RVF/LH language dominance) and negative Als (atypical LVF/RH language dominance) across all language groups were analysed with two $X^{2}$ tests for two 
independent samples. The analysis of the discrete groups revealed no significant differences in participant numbers with positive and non-positive RVF/LH advantage for ACCs, $X^{2}=9.24, d f=5, p=.100$, and RTs, $X^{2}=0.49, d f=5, p=.993$ (Table 5).

Table 5. Absolute number of participants (and percentages) speaking Dutch (DU), English (EN), French (FR), German (GE), Italian (IT) and Norwegian (NO) with a positive Asymmetry Index (AI) in ACCs and RTs. Positive Als indicate a RVF/LH advantage.

\begin{tabular}{lccccccc}
\hline & DU & EN & FR & GE & IT & NO & TOTAL \\
\hline ACCs & 93 & 43 & 72 & 119 & 60 & 47 & 434 \\
& $(85.3)$ & $(81.1)$ & $(83.7)$ & $(93.7)$ & $(85.7)$ & $(92.2)$ & $(87.5)$ \\
RTs & 82 & 42 & 65 & 96 & 52 & 38 & 375 \\
& $(75.2)$ & $(79.2)$ & $(75.6)$ & $(75.6)$ & $(74.3)$ & $(74.5)$ & $(75.6)$ \\
\hline N & 109 & 53 & 87 & 127 & 70 & 51 & 496 \\
& $(100)$ & $(100)$ & $(100)$ & $(100)$ & $(100)$ & $(100)$ & $(100)$ \\
\hline
\end{tabular}

Accuracies. The Als for ACCs (\%) were subjected to a 2 (sex) x 6 (language group) ANCOVA with handedness as covariate. The ANCOVA revealed a significant intercept effect, $F(1,442)=138.36, p<.00001, \eta_{p}^{2}=.24$, indicating that the mean Al of 15.54 ( \pm 0.81) differed significantly from zero (symmetry). The main effect of language group showed only a trend, $F(5,442)=2.05, p=.071, \eta_{p}^{2}=.023$, indicating marginal differences in the degree of language lateralisation across language groups. Italian speaking participants had numerically the largest asymmetry (19.01 \pm 2.02$)$, followed by German (17.98 \pm 1.77$)$, Norwegian (16.80 \pm 2.16$)$, French $(14.53 \pm 1.96)$, Dutch (12.56 \pm 1.79$)$ and English speaking participants (12.36 \pm 2.29$)$. However, none of these differences between language groups was significant, all $p>.05$. No 
further main effect or interaction was significant, all $F \leq 1.86$, all $p \geq .100$.

Response times. The same ANCOVA for Als (with inverted prefixes) for RTs also revealed a significant intercept effect, $F(1,442)=49.76, p<.00001, \eta_{p}{ }^{2}=.101$, with the overall estimated marginal mean 3.64 ( \pm 0.32$)$. Further, there was a significant main effect of language group, $F(5,442)=2.26, p=.048, \eta_{p}{ }^{2}=.026$. However, post hoc tests revealed no significant group differences (all $p \geq .086$ ). No other effect was significant, all $F \leq 0.74$, all $p \geq .596$.

First versus second language

Here, we investigated whether participants who speak a particular language as first or second language differ in language lateralisation as measured with the TLDT. As shown in Table 2, only three languages qualified for this analysis (English, French, and German). Participants speaking Dutch or Italian as second language were underrepresented in the current sample ( $n=0$ and $n=6$, respectively) and therefore were excluded from the analysis. Given that sex did not reveal any significant interaction with visual half-field in the previous analyses, sex was not included here. Handedness was again included as covariate.

Accuracies. ACCs (\%) in word trials were subjected to three separate $2(\mathrm{LVF}, \mathrm{RVF}) \times 2$ ( $1^{\text {st }}$ language, $2^{\text {nd }}$ language) ANCOVA (separate for each language). The analysis revealed significant main effects of visual half-field (RVF/LH advantage) for English, $F(1,274)=54.96, p<.000001, \eta_{p}^{2}=.167$, French, $F(1,136)=66.35, p<.000001, \eta_{p}^{2}$ $=.328$, and German, $F(1,101)=27.42, p<.000001, \eta_{p}{ }^{2}=.213$. Although both English 
groups differed significantly in the overall performance ( $1^{\text {st }}$ language: $72.21 \pm 1.71$, $2^{\text {nd }}$ language $\left.64.60 \pm 0.82\right)$, the VHF $\times$ group interaction was not significant, $F(1,274)$ $=0.65, p=.422, \eta_{p}^{2}=.002$. For French and German, neither the main effect of group $\left(1^{\text {st }}\right.$ language, $2^{\text {nd }}$ language $)$, nor the interaction between VHF and group approached significance, both all $F<1.93, p>.168, \eta_{p}^{2}<.019$. Mean accuracy and standard errors are shown in Figure 3.

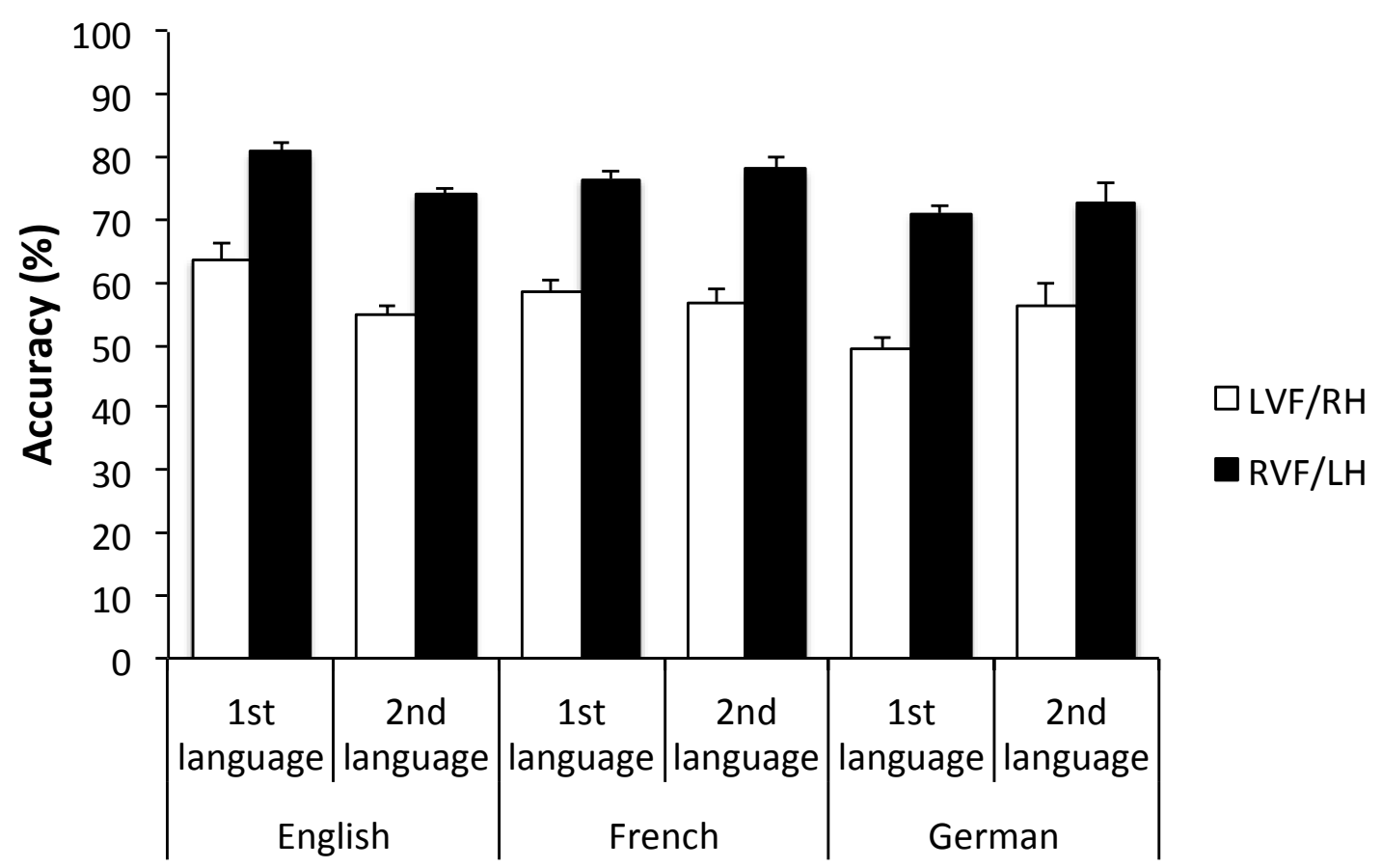

Figure 3. Mean accuracy (\%) and standard errors for both visual half-fields (LVF/RH, RVF/LH) in three language groups (English, French, German) according to acquisition as first/native or second/non-native language. Only three language groups were included because of low numbers of participants speaking Dutch and Italian as second language.

Response times. The same ANCOVA for RTs of correct word trials again revealed significant main effects of visual half-field (RVF/LH advantage) for English, $F(1,274)=$ 
25.04, $p=.000001, \eta_{p}^{2}=.084$, French, $F(1,136)=15.70, p=.0001, \eta_{p}^{2}=.103$, and German, $F(1,101)=10.23, p<.002, \eta_{p}^{2}=.092$. Apart from significant group differences in RTs ( $1^{\text {st }}$ language: $786 \pm 11.3,2^{\text {nd }}$ language: $\left.731 \pm 14.6\right)$ in the French group, $F(1,136)=8.27, p=.005, \eta_{p}{ }^{2}=.057$, all three language groups did not show any further main effect of group or interaction between VHF and group, all $F<1.56$, $p>.213, \eta_{p}{ }^{2}=.011$. Mean response times and standard errors are shown in Figure 4.

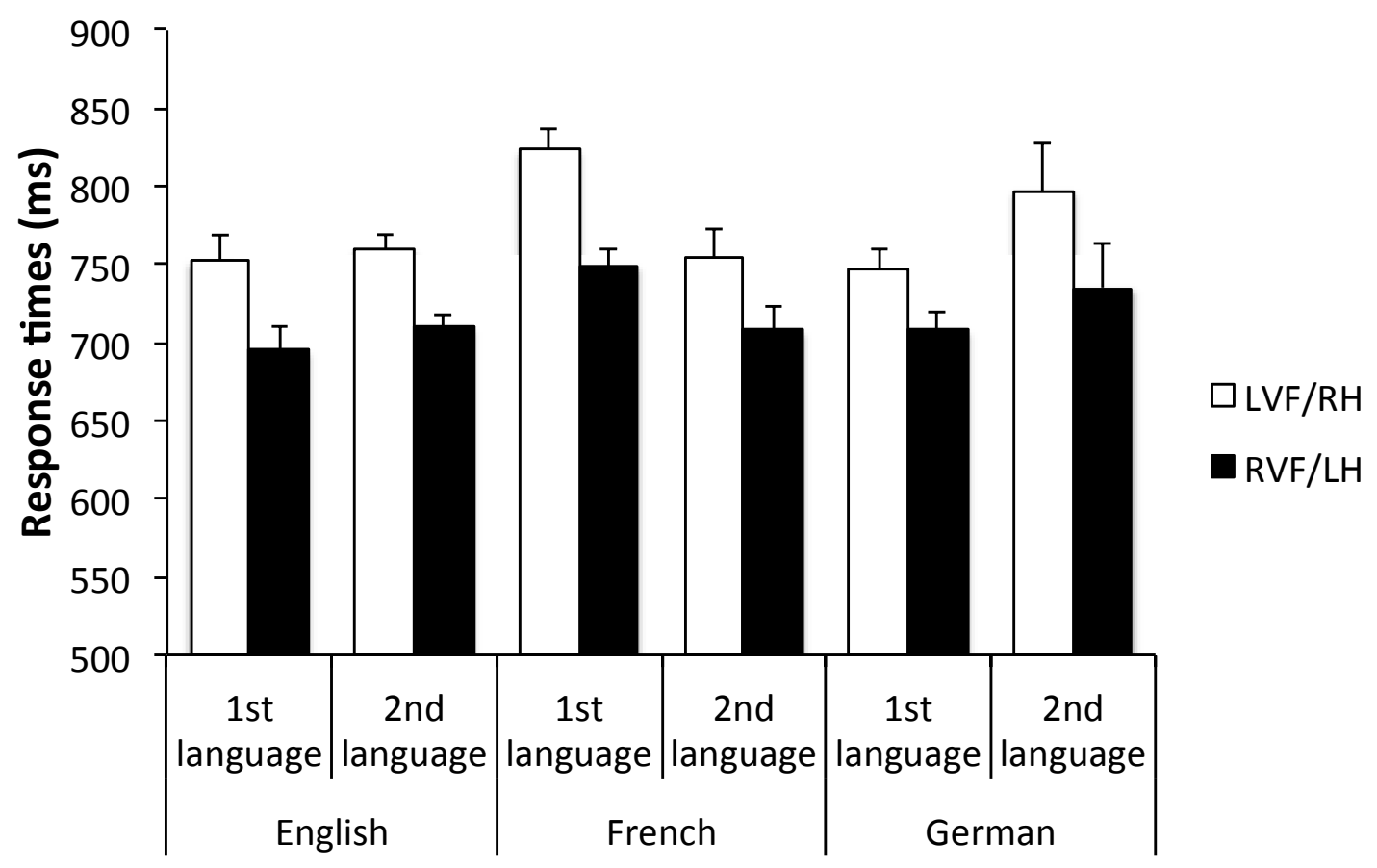

Figure 4. Mean RTs (ms) and standard error means for both visual half-fields (LVF/RH, RVF/LH) in three language groups (English, French, German) according to acquisition as first/native or second/non-native language. Only three language groups were included because of low numbers of participants speaking Dutch and Italian as second language.

Language lateralisation in bilinguals/multilinguals

Accuracies. A 2 (LVF, RVF) $\times 3$ (monolinguals, early bilinguals, late bilinguals) 
ANCOVA on ACCs in word trials revealed a significant RVF/LH advantage, $F(1,400)=$ $139.07, p<.000001, \eta_{p}^{2}<.258$. Neither the main effect of group, $F(2,400)=0.15, p$ $=.859, \eta_{p}^{2}<.001$, nor the VHF $\times$ group interaction was significant, $F(2,400)=0.57, p$ $=.567, \eta_{p}^{2}<.003$. Mean accuracy and standard errors are shown in Figure 5 .

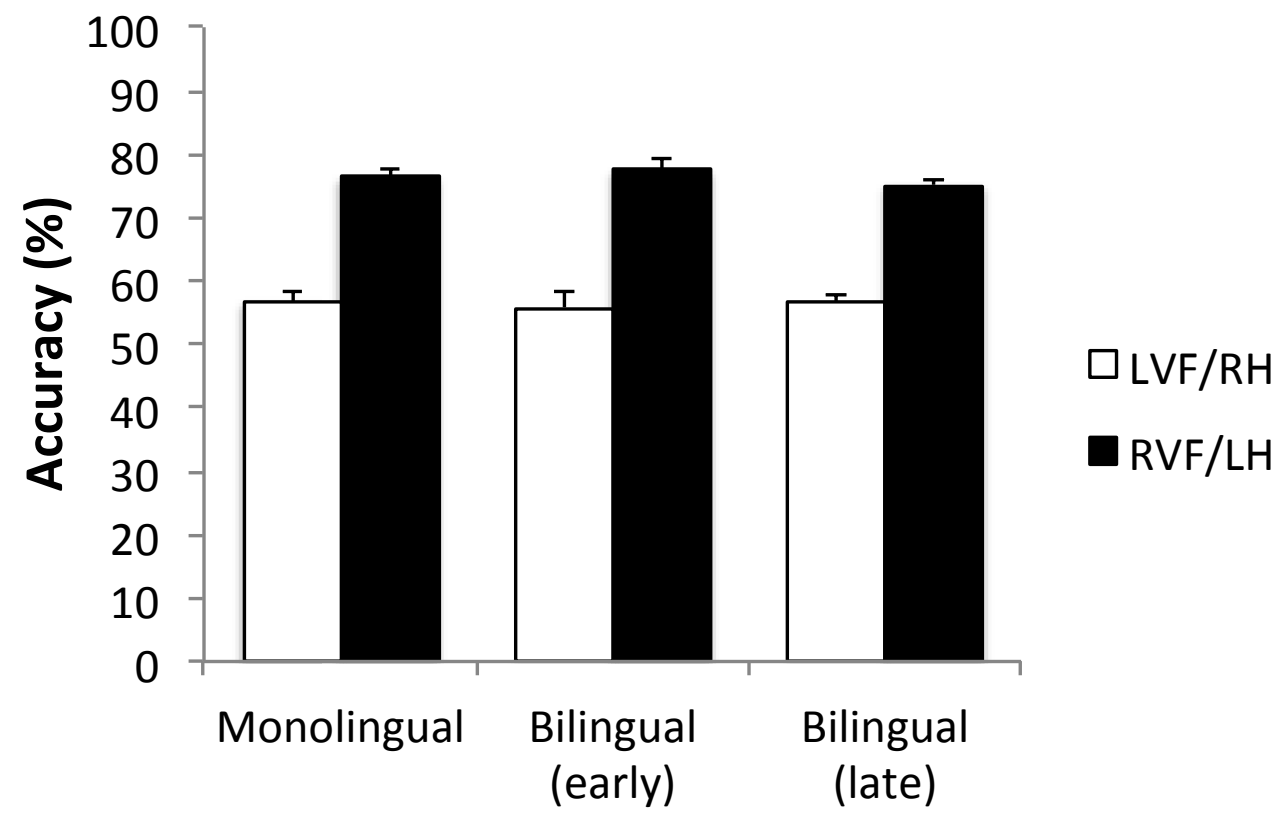

Figure 5. Mean ACC (\%) and standard error means for both visual half-fields (LVF/RH, RVF/LH) in monolinguals, early bilinguals (at age $0-5$ years), and late bilinguals (at age 6-22 years).

Response times. For RTs of correct word trials, the same ANCOVA revealed a significant group effect, $F(2,400)=9.94, p<.001, \eta_{p}{ }^{2}=.047$, and the interaction between VHF $\times$ group was significant, $F(2,400)=7.20, p<.001, \eta_{p}{ }^{2}=.035$, both with small effect sizes. Although all three groups showed significant RVF/LH advantages, all $t>5.00$, all $p<.0001$ (Figure 6), the late bilingual group revealed the smallest effect size (Cohen's $d=0.508)$, followed by the early bilingual group $(d=0.778)$, and finally the monolingual group $(d=0.753)$. The group differences in RVF/LH 
advantages remained when the $\mathrm{Al}$, controlling for overall performance differences in RT, entered the ANCOVA, $F(2,400)=5.89, p=.003, \eta_{p}{ }^{2}=.029$. Post hoc tests revealed language lateralisation for the late bilingual group to be significantly smaller than for the early bilingual group $(p=.024)$ and monolinguals $(p=.021)$. It should be noted that these participants also were the fastest. Mean response times and standard errors are shown in Figure 6.

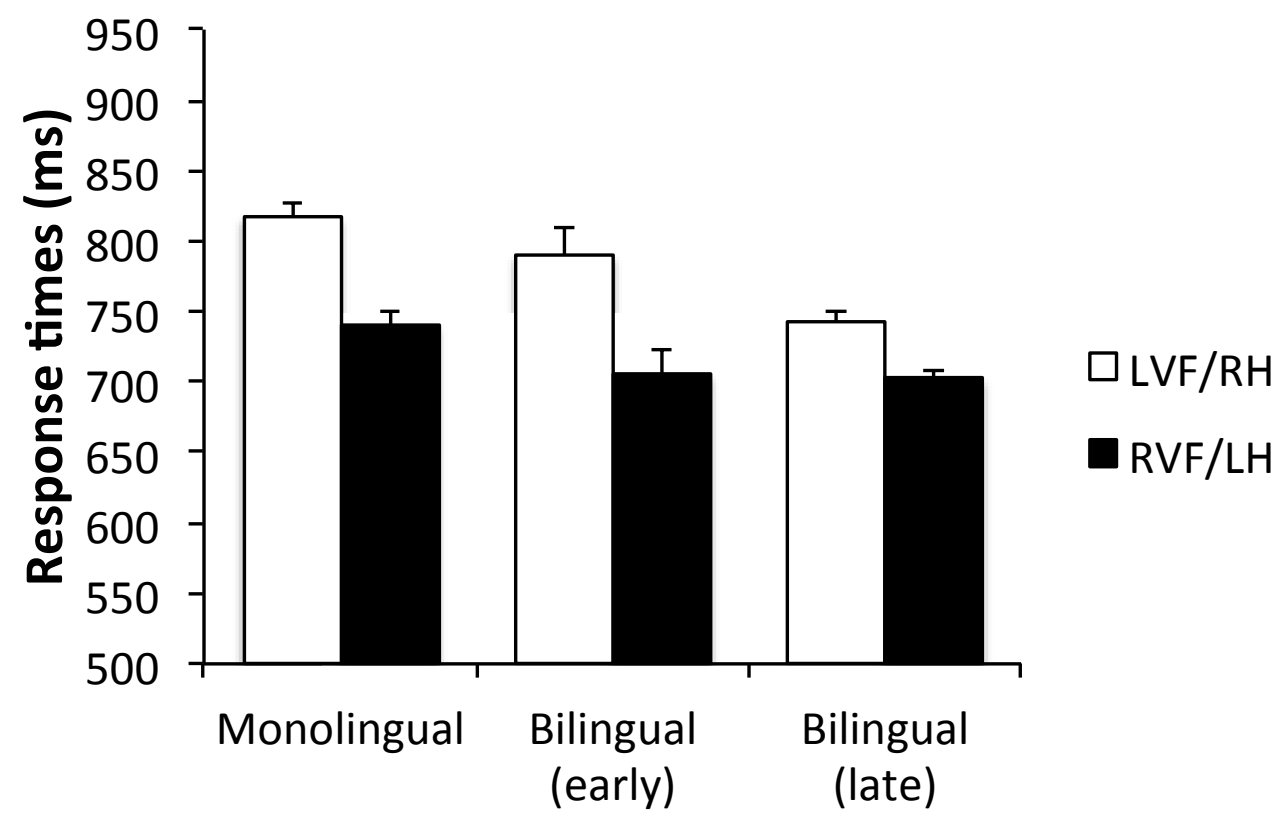

Figure 6. Mean RTs (ms) and standard errors for both visual half-fields (LVF/RH, RVF/LH) in monolinguals, early bilinguals (at age $0-5$ years), and late bilinguals (at age 6-22 years).

\section{Asymmetry-performance relationships}

To investigate asymmetry-performance relationships for different language groups, we used partial correlations (controlled for handedness) between Als (sided and absolute) and performances averaged across LVF and RVF for both ACCs and RTs (Boles et al., 2008; Hirnstein, Leask, Rose, \& Hausmann, 2010). For ACCs, we found 
consistently small, but significant negative partial correlations between Als and overall ACCs. For RTs, partial correlations were mainly positive, although only some of them were significant, for example, for the total sample. The asymmetryperformance relationships were consistently stronger when absolute Als were taken into account. The results for both ACCs and RTs point into the same direction, that is, the smaller participants' asymmetry, the better their performance (i.e., higher ACCs and faster RTs) (Table 6). It should be noted, however, that several previous studies also reported smaller functional difference between hemispheres with generally faster responses.

Table 6. Partial correlation coefficients (controlled for handedness) for signed (directional) and absolute asymmetry indices (Als) and overall performances (averaged across LVF and RVF) for ACCs and RTs according to language group (first and second language) and monolingual/bilingual group. Significant correlations ( $p<$ $.01)$ are shown in bold.

\begin{tabular}{|c|c|c|c|c|c|}
\hline \multirow[t]{2}{*}{ Language/Group } & \multirow[t]{2}{*}{ df } & \multicolumn{2}{|c|}{ Hit rates } & \multicolumn{2}{|c|}{ Response times } \\
\hline & & Signed Al & Absolute Al & Signed Al & Absolute $\mathbf{A}$ \\
\hline Dutch $\left(1^{\text {st }}\right)$ & 106 & -.391 & -.580 & .069 & .215 \\
\hline English (1 $\left.1^{\text {st }}\right)$ & 49 & -.570 & -.552 & .164 & .174 \\
\hline French $\left(1^{\text {st }}\right)$ & 83 & -.234 & -.477 & .131 & .243 \\
\hline German $\left(1^{\text {st }}\right)$ & 84 & -.335 & -.340 & -.018 & .058 \\
\hline Italian $\left(1^{\text {st }}\right)$ & 67 & -.108 & -.319 & .221 & .164 \\
\hline Norwegian $\left(1^{\text {st }}\right)$ & 48 & -.403 & -.504 & .079 & .020 \\
\hline English $\left(2^{\text {nd }}\right)$ & 222 & -.392 & -.496 & .120 & .128 \\
\hline French $\left(2^{\text {nd }}\right)$ & 50 & -.401 & -.514 & .255 & .464 \\
\hline German $\left(2^{\text {nd }}\right)$ & 14 & -.241 & -.526 & .544 & .146 \\
\hline Monolingual & 117 & -.362 & -.562 & .243 & .331 \\
\hline Bilinguals (early) & 40 & -.283 & -.385 & .119 & .243 \\
\hline Bilinguals (late) & 238 & -.380 & -.486 & .086 & .148 \\
\hline Total & 452 & -.363 & -.491 & .154 & .214 \\
\hline
\end{tabular}




\section{Discussion}

The current study investigated language lateralisation for lexical word/non-word decisions of translingual stimuli in a large sample of more than 500 participants from seven European countries (Belgium, UK, Germany, Italy, The Netherlands, Norway, Switzerland), speaking English, German, French, Dutch, Italian and/or Norwegian. The TLDT was developed in order to facilitate the test of hemispheric dominance for language in an environment in which individuals are likely to speak different and several languages and to facilitate comparisons of results between studies around the globe. The TLDT was designed following procedural recommendations (see Beaumont, 1982; Bourne, 2006; Hunter \& Brysbaert, 2008) and selected short words and non-words of 4 to 6 letters, presented tachistoscopically for $100 \mathrm{~ms}$ and simultaneously to LVF and RVF, and in a sufficiently large number of more than 250 word and non-word trials. As expected, based on our previous work (Willemin et al. (2016), the TLDT revealed a consistent RVF/LH advantage, most strongly so for accuracy, explaining more than $26 \%$ of total variance. The corresponding RVF/LH advantage for RT accounted for $10 \%$ of total variance. With regards to comparisons of i) different language groups, ii) first versus second language speakers, and iii) monolinguals versus early and late bilinguals, we found mainly minor group differences in language lateralisation as measured with TLDT, irrespective of overall accuracy and RT differences. Thus, the current findings extend the results of a previous study that administered TLDT to a Swiss sample (Willemin et al., 2016). The results suggest that TLDT is a reliable tool to test for the well-established RVF/LH 
advantage in language processing frequently found in properly designed VHF tests (Hunter \& Brysbaert, 2008).

The results revealed some differences between language groups in overall ACCs and RTs. Mean accuracy was generally higher in the Dutch and English samples as compared to the German, Italian, and Norwegian samples, with the French speakers lying in between. For response latencies, the Dutch speakers also responded faster than the German sample, with the latter group responding faster than the English, French, Norwegian, and Italian samples, speaking in general against a speed-accuracy trade-off. Language group differences in frequency of the word stimuli might have contributed, at least partially, to the overall performance differences between countries, such as the lower word frequencies in German (see also Willemin et al., 2016). However, the small variations between language groups in the RVF/LH advantage make it rather unlikely that these factors played a major role in language lateralisation as measured with TLDT. In fact, we found only one single significant group difference in RTs between the Dutch and Italian samples which disappeared once overall RT in each group was taken into account (using Als). A large proportion of participants (76.0\%) reported to speak at least one additional language. Therefore, we performed additional analyses investigating whether language lateralisation as measured with TLDT differed between participants speaking English, French, and German as first or second language. Sample sizes for the other language groups were insufficient for this analysis. In addition, we aimed to contribute to the on-going debate on potential differences in language lateralisation in monolingual and early and late bi-/multilingual 
participants with second language acquisition before and after the age of 6 years (see also Willemin et al., 2016).

Addressing the first point, individuals speaking English, French, or German as first language showed generally higher ACCs and faster RTs than participants speaking the same languages as second language. However, the group difference in overall performance did not interact with VHF, indicating similar degrees of language lateralisation in all language groups. This finding is interesting because lateralisation in first and second languages is usually investigated in bilingual participants speaking two (or more) different languages (within-subject) (for a review, see Hull \& Vaid, 2006, 2007; Vaid \& Hall, 1991), without comparing lateralisation between groups in which first and second languages are identical (between-subject).

The results are in line with a meta-analysis on language lateralisation in bilinguals (Hull \& Vaid, 2007) that also revealed that language lateralisation in the second language mirrors language lateralisation in the first language, at least in late bilinguals proficient in the second language. This finding is consistent with existing models of neurofunctional organization of grammar and the lexicon that are based on language proficiency. In particular, both the declarative/procedural (Ullman, 2001) and the convergence model (Green, 2003) predict similar LH dominance for proficient first and second languages. It should be noted that the vast majority of participants in the current study were recruited from university student populations, suggesting relatively high levels in proficiency in participants' second language. For example, $52 \%$ of the total sample reported to speak English as second language. 
Given that English is a prerequisite for many subjects in higher education, we can assume high proficiency for the majority of the current sample.

Apart from proficiency, age of acquisition of the second language is another relevant factor for language lateralisation. In fact, Hull and Vaid (2007) revealed a robust effect of acquisition age on language lateralisation regardless of proficiency. The direction of the difference was for increased $\mathrm{RH}$ involvement in early relative to late bilinguals which corresponds to an earlier meta-analysis by the authors (Hull \& Vaid, 2006) showing bilateral activation for infant onset bilinguals and LH dominance for late onset bilinguals in their first language.

In contrast to the bilateral hemispheric involvement in early bilinguals (Hull \& Vaid, 2006; Vaid \& Hall, 1991), the current study found a significant RVF/LH advantage regardless of how many languages were acquired and when. This finding corroborates a recent neuroimaging study that found neural convergence for different language processes in highly proficient bilinguals to be independent of acquisition age (Consonni et al., 2013). However, although monolinguals as well as early and late bi/multilinguals of the current study showed a significant RVF/LH advantage in ACCs and RTs, language lateralisation was significantly reduced in late bilinguals when the asymmetry in RTs was indexed, taking overall performance into account.

In accordance with the current study, a recent meta-analysis on neuroimaging data (Liu \& Cao, 2016) found that late bilinguals, compared to early bilinguals involve more additional, including bilateral, brain regions in second than first language processing - a finding in line with the initial formulations of the Age of 
Language Acquisition Hypothesis (Vaid, 1983) that predicted increased RH

involvement for late bilinguals relative to monolinguals and early bilinguals.

Finally, we investigated asymmetry-performance relationship as measured with TLDT. A simple and common procedure to determine the asymmetryperformance relationship is to correlate degree of lateralisation, as reflected by Als in ACCs and RTs, with the overall performance, as measured by the averaged LVF/RH and RVF/LH performance in ACCs and RTs (e.g., Boles et al., 2008; Hirnstein et al., 2010). The analyses revealed consistently significant negative correlations for ACCS for all language groups and regardless of whether and when a second language was acquired. This consistency indicates that the smaller the asymmetry, the better participants' ACC. For RTs, the relationship was smaller, mainly significant for the total and monolingual sample, but pointed into the same direction, that is better performance (faster responses) when asymmetries were reduced.

The asymmetry-performance relationships found in the present study are partly consistent with previous findings (e.g., Boles et al., 2008) but conflicting with others (e.g., Chiarello et al., 2009), suggesting inconsistency in the literature and the relevance of individual and task-related factors (Hirnstein et al., 2010). For example, Boles et al. (2008) showed in a large sample of 789 right-handers that asymmetryperformance relationships vary by task. In line with the current study, Boles et al. (2008) found better performance in participants with smaller asymmetries when, for example, visual lexical tasks were administered, while other laterality tasks were performed better by those with larger asymmetries (e.g., dichotic listening with syllables and words). The authors explained the task-specific effects by a neurodevelopmental theory which assumes that larger asymmetries are associated 
with better performance for processes that are acquired early (auditory linguistic processes). On the other hand, smaller asymmetries are associated with better performance for visual lexical processes that are acquired somewhat later during ontogenesis, and are possibly related to individual differences in maturation of the corpus callosum.

In line with Boles et al. (2008) and the present study, Hirnstein et al. (2010) also found significant negative asymmetry-performance relationship for a verbal VHF task (i.e., word matching) in accuracy (only), suggesting that extremely high asymmetry degrees are detrimental, and that the overall performance will increase when the RVF/LH advantage in this task is low. However, Chiarello et al. (2009) found reliable positive asymmetry-performance relationships for word recognition VHF tasks (i.e., lexical decision, word naming, non-word naming, masked word recognition) in a sample of 200 young adults, indicating that larger visual lexical asymmetries were associated with better (reading) performance, especially for consistent handers. No asymmetry-performance relationships were found for semantic VHF tasks (semantic decision, category and verb generation).

In addition to these individual and task-related factors that might account for some of the inconsistencies reported in the literature, there is evidence that asymmetry-performance relationships are generally complex and might not necessarily be linear. For example, a recent large-scale dichotic listening study including 1839 participants found a u-shaped relationship between degree in language lateralisation and overall accuracy which consistently emerged regardless of handedness and sex (Hirnstein, Hugdahl, \& Hausmann, 2014). The non-linear relationship suggested that individuals with symmetric brain organization performed 
best and performance deteriorated with increasing asymmetry, regardless of its direction - a finding partly in line with the present study that also found the strongest (linear) relationship for absolute Als.

It should be noted, however, that the approach of calculating these correlations has been criticised because the relationship between hemispheric asymmetries and cognitive performance might be confounded by the correlation of RVF/LH and LVF/RH performances (Annett \& Manning, 1990, Boles et al., 2008) and an alternative approach has been proposed in which the observed relationship between lateralisation and performance is mathematically modelled (Leask \& Crow, 2006; Hirnstein, Leask, Rose, \& Hausmann, 2010). Furthermore, the calculation of asymmetry indices as the Al used here and in Hirnstein et al. (2014) has been criticized (see Boles \& Barth, 2011). One limitation related to the previous issue is the relatively large number of participants who were excluded mainly because of performance issues (i.e., ACCs in the dominant and non-dominant visual field below and above chance, respectively), suggesting that the TLDT was relatively demanding. This implies that, for clinical use or testing elderly participants, experimenters might want to reduce task difficulty by increasing stimulus presentation duration. For example, Cherry, Hellige, and McDowd (1995) have dynamically adjusted presentation times (i.e., an incorrect response lengthened exposure duration on the subsequent trial in increments of $15 \mathrm{~ms}$ and vice versa). However, it is recommended that stimulus presentation is limited to a maximum exposure duration of $180 \mathrm{~ms}$, with exposure ideally limited to $150 \mathrm{~ms}$ if the task is simple (Bourne, 2006). If presentation times need more adjustments, we recommend 
controlling for eye fixation with, for example, an eye-tracking system or electrooculography (Bourne, 2006).

Overall, the current findings indicate that TLDT is a reliable VHF task to assess hemispheric dominance for language, especially with accuracy as dependent variable. We found that the robust RVF/LH advantage measured on the population level showed only minor variation across language groups and depending on how many languages were acquired and when. The strong RVF/LH advantage was relatively independent from individual factors such as sex. Participants in some samples (Dutch) performed better than other samples (Italian), but this group difference may partly be explained by group differences in word frequency or language proficiency and language acquisition (for bi/multilinguals). Unfortunately, the present study did not include language tests to measure participants' proficiency in the first and additional languages, which is a clear limitation. If future studies aim to compare language lateralisation in (clinical) individuals and groups that differ in overall performance, we recommend using an asymmetry index on accuracy. It should be noted, however, that we did not find a consistent relationship between Als and language proficiency or acquisition in a previous study using a verbal VHF task (Hausmann, Durmusoglu, Yazgan \& Güntürkün, 2004, but also see Willemin et al. (2016) who reported that enhanced vocabulary knowledge was related to a RH shift in early bilinguals and a LH shift in late bilinguals). Although the present results suggest a negative relationship between degree in asymmetry and general performance in TLDT, language group differences in performance did only marginally affect RVF/LH advantage in this task, making the task a reliable and easy to administer measurement of language lateralisation that can be applied in 
experimental settings as well as in the clinical context, for example in localising language functions in patients with unilateral brain lesions, across linguistic and national boundaries.

\section{References}

Allison, T., Puce, A., \& McCarthy, G. (2000). Social perception from visual cues: role of the STS region. Trends in Cognitive Sciences, 4(7), 267-278. doi:10.1016/S1364-6613(00)01501-1.

Annett, M., \& Manning, M. (1990). Arithmetic and laterality. Neuropsychologia, 28(1), 61-69.

Beaumont, J. G. (1982). Studies with verbal stimuli. In J. G. Beaumont (Ed.), Divided visual field studies of cerebral organisation (pp. 58-86). London: Academic Press.

Bishop, D. V. M. (2013). Cerebral asymmetry and language development: cause, correlate, or Consequence? Science, 340, (6138), 1230531. DOI:10.1126/science.1230531

Boles, D. B. (1987). Reaction time asymmetry through bilateral versus unilateral stimulus presentation. Brain and Cognition, 6, 321-333.

Boles, D. B. (1990). What bilateral displays do. Brain and Cognition, 12, 205228. 
Boles, D. B. (1994). An experimental comparison of stimulus type, display type and input variable contributions to visual field asymmetry. Brain and Cognition, 24, 184-197.

Boles, D. B., \& Barth, J. M. (2011). “Does degree of asymmetry relate to performance?" A critical review. Brain and Cognition, 76, 1-4.

doi:10.1016/j.bandc.2011.01.013

Boles, D. B., Barth, J. M., \& Merrill, E. C. (2008). Asymmetry and performance: toward a neurodevelopmental theory. Brain and Cogniton, 66, 124-139. doi:10.1016/j.bandc.2007.06.002

Bourne, V. J. (2006). The divided visual field paradigm: Methodological considerations. Laterality, 11(4), 373-393. doi: 10.1080/13576500600633982

Bortz, J., Lienert, G. A., \& Boehnke, K. (2000). Verteilungsfreie Methoden der Biosta- tistik. Springer, Heidelberg.

Broca, P. (1865). Sur le siège de la faculté du langage articulé. Bulletins de la Société d'anthropologie de Paris, 6(1), 377-393. doi:10.3406/bmsap.1865.9495

Brysbaert, M., Buchmeier, M., Conrad, M., Jacobs, A.M., Bölte, J., \& Böhl, A. (2011). The word frequency effect: A review of recent developments and implications for the choice of frequency estimates in German. Experimental Psychology, 58, 412-424. 
Brysbaert, M., \& D’Ydewalle, G. (1990). Tachistoscopic presentation of verbal stimuli for assessing cerebral dominance: Reliability data and some practical recommendations. Neuropsychologia, 28, 443-455.

Brysbaert, M., \& Stevens, M. (2018). Power Analysis and Effect Size in Mixed Effects Models: A Tutorial. Journal of Cognition, 1, 9. doi:10.5334/joc.10

Bundesamt für Statistik, Schweizerische Eidgenossenschaft (2018). Sprachen. (Retrieved July 16, 2018, from http://www.bfs.admin.ch/bfs/de/home/statistiken/bevoelkerung/sprachenreligionen/sprachen.html).

Carey, D. P., \& Johnstone, L. T. (2014). Quantifying cerebral asymmetries for language in dextrals and adextrals with random-effects meta analysis. Frontiers in Psychology, 5, 1128. doi:10.3389/fpsyg.2014.01128

Cherry, B. J., Hellige, J. B., \& McDowd, J. M. (1995). Age differences and similarities in patterns of cerebral hemispheric asymmetry. Psychology and Aging, 10(2), 191-203.

Chiarello, C., Dronkers, N. F., \& Hardyck, C. (1984). Choosing sides: On the variability of language lateralization in normal subjects. Neuropsychologia, 22(3), 363-373. doi:10.1016/0028-3932(84)90082-4.

Chiarello, C., Welcome, S. E., Halderman, L. K., \& Leonard, C. M. (2009). Does degree of asymmetry relate to performance? An investigation of word recognition 
and reading in consistent and mixed handers. Brain and Cognition, 69, 521-530.

doi:10.1016/j.bandc.2008.11.002

Consonni, M., Cafiero, R., Marin, D., Tettamanti, M., ladanza, A., Fabbro, F., \& Perani, D. (2013). Neural convergence for language comprehension and grammatical class production in highly proficient bilinguals is independent of age of acquisition. Cortex, 49, 1252-1258.

Cornelissen, P., Tarkiainen, A., Helenius, P., \& Salmelin, R. (2003). Cortical effects of shifting letter position in letter strings of varying length. Journal of Cognitive Neuroscience, 15(5), 731-746. doi:10.1162/jocn.2003.15.5.731

Crepaldi, D., Keuleers, E., Mandera, P., \& Brysbaert, M. (2013). SUBTLEX-IT. Retrieved from http://crr.ugent.be/subtlex-it/ (July 5, 2018)

Davis, C. J. (2005). N-Watch: A program for deriving neighbourhood size and other pyscholinguistic statistics. Behaviour Research Methods, 37, 65-70.

Fennell, E. B., Bowers, D., Satz, P. (1977). Within-modal and cross-modal reliabilities of two laterality tests. Brain and Language, 4(1), 63-69. doi:10.1016/0093-934X(77)90006-2

Forster, K. I., \& Forster, J. C. (2003). DMDX: A windows display program with millisecond accuracy. Behavior Research Methods, Instruments, \& Computers, 35(1), $116-124$ 
Gazzaniga, M., Bogen, J., \& Sperry, R. (1965). Observations on visual perception after disconnexion of the cerebral hemispheres in man. Brain, 88(2), 221-236. doi: $10.1093 / \mathrm{brain} / 88.2 .221$

Geffen, G., Bradshaw, J. L., \& Nettleton, N. C. (1972). Hemispheric asymmetry: verbal and spatial encoding of visual stimuli. Journal of Experimental Psychology, 95, 25-31.

Green, D. (2003). Neural basis of lexicon and grammar in L2 acquisition: The convergence hypothesis. In R. van Hout, A. Hulk, F. Kuiken, \& R. Towell (Eds.), The interface between syntax and the lexicon in second language acquisition (pp. 197208). Amsterdam: John Benjamins.

Hausmann, M., Becker, C., Gather, U., \& Güntürkün, O. (2002). Functional cerebral asymmetries during the menstrual cycle: a cross sectional and longitudinal analysis. Neuropsychologia, 40, 808-816.

Hausmann, M., Durmusoglu, G., Yazgan, Y., \& Güntürkün, O. (2004). Evidence for reduced hemispheric asymmetries in non-verbal functions in bilinguals. Journal of Neurolinguistics, 17, 285-299.

Hausmann, M., \& Güntürkün, O. (1999). Sex differences in functional cerebral asymmetries in a repeated measures design. Brain and Cognition, 41(3), 263-275. $\underline{\text { doi:10.1006/brcg.1999.1126 }}$

Hausmann, M., Hodgetts, S., \& Eerola, T. (2016). Music-induced changes in functional cerebral asymmetries. Brain and Cognition, 104, 58-71. 
Hickok, G., \& Poeppel, D. (2007): The cortical organization of speech processing. Nature Reviews Neuroscience, 8, 393-402.

Hines, D., Fennell, E. B., Bowers, D., \& Satz, P. 1980. Left-handers show greater test-retest variability in auditory and visual asymmetry. Brain and Language, 10, 208-211.

Hirnstein, M., Hausmann, M., \& Güntürkün, O. (2008). The evolutionary origins of functional cerebral asymmetries in humans: Does lateralization enhance parallel processing? Behavioural Brain Research, 187, 297-303.

Hirnstein, M., Hugdahl, K., \& Hausmann, M. (2014). How brain asymmetry relates to performance - a large-scale dichotic listening study. Frontiers in Psychology, 4, 997. doi:10.3389/fpsyg.2013.00997

Hirnstein, M., Leask, S., Rose, J., \& Hausmann, M. (2010). Disentangling the relationship between hemispheric asymmetry and cognitive performance. Brain and Cognition, 73, 119-127. doi: 10.1016/j.bandc.2010.04.002

Hugdahl, K. (2000). Lateralization of cognitive processes in the brain. Acta Psychologica, 105(2-3), 211-235. doi:10.1016/\$0001-6918(00)00062-7

Hugdahl, K. (2011). Fifty years of dichotic listening research - still going and going and.... Brain and Cognition, 76(2), 211-213. doi:10.1016/j.bandc.2011.03.006 Hull, R., \& Vaid, J. (2006). Laterality and language experience. Laterality, 11(5), 436-464. 
Hull, R., \& Vaid, J. (2007). Bilingual language lateralization: A meta-analytic tale of two hemispheres. Neuropsychologia, 45(9), 1987-2008.

Doi:10.1016/j.neuropsychologia.2007.03.002

Hunter, Z. R., \& Brysbaert, M. (2008). Visual half-field experiments are a good measure of cerebral language dominance if used properly: Evidence from fMRI. Neuropsychologia, 46(1), 316-325. doi:10.1016/i.neuropsychologia.2007.07.007

lacoboni, M., \& Zaidel, E. (1996). Hemispheric independence in word recognition: Evidence from unilateral and bilateral presentations. Brain and Language, 53, 121-140. doi:10.1006/brln.1996.0040

Keuleers, E., \& Brysbaert, M. (2010). Wuggy: a multilingual pseudoword generator. Behavior Research Methods, 42(3), 627-33. doi:10.3758/BRM.42.3.627

Keuleers, E., Brysbaert, M., \& New, B. (2010). SUBTLEX-NL: A new frequency measure for Dutch words based on film subtitles. Behavior Research Methods, 42, 643-650.

Kimura, D. (1961). Cerebral dominance and the perception of verbal stimuli. Canadian Journal of Psychology, 15(3), 166-170. doi: 10.1037/h0083219

Knecht, S., Jansen, A., Frank, A., van Randenborgh, J., Sommer, J., Kanowski, M., et al. (2003). How atypical is atypical language dominance? Neuroimage, 18 , 917-927. 
Krach, S., Chen, L. M., \& Hartje, W. (2006). Comparison between visual halffield performance and cerebral blood flow changes as indicators of language dominance. Laterality, 11(2), 122-140. doi:10.1080/13576500500384975

Lassonde, M., \& Bryden, M. P. (1990). Dichotic listening, callosal agenesis and cerebral laterality. Brain and Language, 39(3), 475-481. doi:10.1016/0093$934 \times(90) 90154-9$

Lassonde, M., Bryden, M. P., \& Demers, P. (1990). The corpus callosum and cerebral speech lateralization*1. Brain and Language, 38(2), 195-206. doi:10.1016/0093-934X(90)90110-3

Leask, S. J., \& Crow, T. J. (2006). A single optimum degree of hemispheric specialisation in two tasks, in two UK national birth cohorts. Brain and Cognition, 62(3), 221-227.

Liu, H., \& Cao, F. (2016). Li and L2 processing in the bilingual brain: a metaanalysis of neuroimaging studies. Brain and Language, 159, 60-73.

Mohr, C., Michel, C. M., Lantz, G., Ortigue, S., Viaud-Delmon, L., Landis, T., \& Viaud-Delmon, I. (2005). Brain state-dependent functional hemispheric specialization in men but not in women. Cerebral Cortex, 15(9), 1451-1458. doi: 10.1093/cercor/bhi025

Morris, S. B., \& DeShon, R. P. (2002). Combining effect size estimates in metaanalysis with repeated measures and independent-groups designs. Psychological Methods, 7, 105-125. 
New, B., Pallier, C., Brysbaert, M., \& Ferrand, L. (2004). Lexique 2 : A new French lexical database. Behavior Research Methods, Instruments, \& Computers, 36(3), 516-524. doi:10.3758/BF03195598

Ocklenburg, S., \& Güntürkün, O. (2018). The lateralized brain: The neuroscience and evolution of hemispheric asymmetries. London: Academic Press.

Oldfield, R. C. (1971). The assessment and analysis of handedness: the Edinburgh inventory. Neuropsychologia, 9(1), 97-113. doi:10.1016/00283932(71)90067-4

Papanicolaou, A. C., Rezaie, R., Narayana, S., Choudhri, A. F., Wheless, J. W., Castillo, E. M., Baumgartner, J. E., \& Boop, F. A. (2014). Is it time to replace the Wada test and put awake craniotomy to sleep? Epilepsia, 55(5), 629-632. doi:10.1111/epi.12569

Rasmussen, T., \& Milner, B. (1975). in Cerebral Localization, K. Zülch, O. Creutzfeldt, G. Galbraith, Eds. (Springer, New York, 1975), pp. 238-257.

Ratcliff, R., Gomez, P., \& McKoon, G. (2004). A diffusion model account of the lexical decision task. Psychological Review, 111(1), 159-182. doi: 10.1037/0033$\underline{295 X .111 .1 .159}$

Rutten, G. J. M., Ramsey, N. F., van Rijen, P. C., \& van Veelen, C. W. M. (2002). Reproducibility of fMRI-determined language lateralization in individual subjects. Brain and Language, 80, 421-437. 
Seghier, M. L. (2008). Laterality index in functional MRI: methodological issues. Magnetic Resonance Imaging, 26, 594-601.

Sperry, R. (1982). Some effects of disconnecting the cerebral hemispheres. Bioscience Reports, 2(5), 265-276. doi:10.1007/BF01115112

Tao, L., Marzecova, A.,Taft, M., Asanowicz, D., \& Wodniecka, Z. (2011). The efficiency of attentional networks in early and late bilinguals: the role of age of acquisition. Frontiers in Psychology, 2, 123. doi:10.3389/fpsyg.2011.00123

Ullman, M. T. (2001). The neural basis of lexicon and grammar in first and second language: the declarative/procedural model. Bilingualism: Language and Cognition, 4(1), 105-122.

Vaid, J. (1983). Bilingualism and brain lateralization. In S. Segalowitz (Ed.), Language functions and brain organization (pp. 315-339). New York: Academic Press.

Vaid, J., \& Hall, D. G. (1991). Neuropsychological perspectives on bilingualism: Right, left and center. In A. Reynolds (Ed.), Bilingualism, multicultur- alism and second language learning: The McGill conference in honour of Wallace E. Lambert (pp. 81-112). Hillsdale, NJ: Lawrence Erlbaum Associates.

Van der Haegen, L., Cai, Q., Seurinck, R., \& Brysbaert, M. (2011). Further fMRI validation of the visual half field technique as an indicator of language laterality: A large-group analysis. Neuropsychologia, 49(10), 2879-2888. 
Van der Haegen, L., Westerhausen, R., Hugdahl, K., \& Brysbaert, M. (2013). Speech dominance is a better predictor of functional brain asymmetry than handedness: A combined fMRI word generation and behavioral dichotic listening study. Neuropsychologia, 51(1), 91-97. doi:10.1016/j.neuropsychologia.2012.11.002

Van Heuven, W.J.B., Mandera, P., Keuleers, E., \& Brysbaert, M. (2014). Subtlex-UK: A new and improved word frequency database for British English. Quarterly Journal of Experimental Psychology, 67, 1176-1190.

Vigneau, M., Beaucousin, V., Herve, P. Y., Duffau, H., Crivello, F., Houde, O., Tzourio-Mazoyer, N. (2006): Meta-analyzing left hemisphere language areas: phonology, semantics, and sentence processing. Neuroimage, 30, 1414-1432.

Voyer, D. (1998). On the reliability and validity of noninvasive laterality measures. Brain and Cognition, 36(2), 209-36. doi:10.1006/brcg.1997.0953

Weis, S., Hausmann, M., Stoffers, B., Vohn, R., Kellermann, T., \& Sturm, W. (2008). Estradiol modulates functional brain organization during the menstrual cycle: an analysis of interhemispheric inhibition. Journal of Neuroscience, 28, 1340113410.

Wernicke, C. (1874). Der aphasische Symptomencomplex: Eine psychologische Studie auf anatomischer Basis. Breslau: Max Cohn \& Weigert.

Willemin, J., Hausmann, M., Brysbaert, M., Dael, N., Chmetz, F., Fioravera, A., Gieruc, K. \& Mohr, C. (2016). Stability of right visual field advantage in an 
international lateralized lexical decision task irrespective of participants' sex, handedness or bilingualism. Laterality, 21, 502-524.

World Medical Association. (2001). World Medical Association Declaration of Helsinki. Ethical principles for medical research involving human subjects. Bulletin of the World Health Organization, 79(4), 373-4. 